\title{
Sleep quality and video game playing: Effect of intensity of video game playing and mental health
}

\author{
Emin Altintas ${ }^{a, *}$, Yasemin Karaca ${ }^{b}$, Timothé Hullaert $^{a}$, Patricia Tassi ${ }^{c}$ \\ a Univ. Lille, EA 4072 - PSITEC - Psychologie : Interactions, Temps, Emotions, Cognition, F-59000 Lille, France \\ ${ }^{b}$ Pediatric intensive care unit, CHU Lille, F-59000 Lille, France \\ ${ }^{c}$ Laboratory of Cognitive Psychology, University of Strasbourg, Strasbourg, France
}

\section{ARTICLE INFO}

\section{Keywords:}

Intensity of video game playing

Mental health

Sleep profile analysis

Sleep quality

Video game duration

\begin{abstract}
A B S T R A C T
The aim of this study was to explore sleep quality in a video game population and to prospect the role of different factors such as sociodemographic data, video game duration, intensity of video game playing, and mental and physical health. Two hundred and seventeen participants (24.40 \pm 6.98 years old) completed an online questionnaire composed of sociodemographic informations, the Pittsburg Sleep Quality Index (PSQI), the Medical Outcomes Study (MOS SF-36), video game play time per week, and intensity of video game playing as defined by Décamps (AIE-Q). We carried out hierarchical cluster analysis on the 7 dimensions of PSQI to determine sleep quality profiles. Two profiles were found: (1) " High sleep quality profile " for $132(60.83 \%)$ participants, and (2) "Low sleep quality profile " for $85(39.17 \%)$ participants. These two profiles were differently associated with video game duration per week, intensity of video game playing, and mental health Sleep quality was positively related to mental health and negatively with intensity of video game playing Intensity of video game playing was a more salient factor to predict poor sleep quality than video game duration.
\end{abstract}

\section{Introduction}

Ever since its introduction by Young (1998), video game addiction has been the subject of research and debate. Its legitimacy has been controversial as we shouldn't tend to over pathologize everyday's life behaviours (Billieux et al., 2015). Though recently, the DSM-V (APA, 2013) added the Internet Gaming Disorder (IGD) as a non-substance addiction in its third section. It defined the main symptoms and classified it as requiring further research. The addiction term sends back to compulsive and excessive consumption of a behaviour in the case of non-substance addiction, and for IGD is currently used interchangeably with the terms problematic use, excessive use or video game addiction when it comes to former research, but should be united under Internet Gaming Disorder.

In a recent large survey on 8 to 18 -year-old American teenagers, $88 \%$ of participants indicated that they regularly play video games. Only $8 \%$ of video game players reported a pathological pattern (Gentile, 2009; Gentile et al., 2017). In the same vein, INSERM (French National Institute for Health and Medical Research) reported that $5 \%$ of the 17-year-olds play video games between 5 and $10 \mathrm{~h}$ per day, and 3 to $5 \%$ play more than ten hours per day in the French population (INSERM, 2014). IGD concerns a limited number of video game players.
In the literature, a dichotomous approach of gaming disorder (e.g., problematic user versus non-problematic user) is prevalent (King et al., 2011; Kuss and Griffith, 2012). But with the complexity of gaming characteristics a more ecological approach of IGD should be investigated. The assessment of video game playing proposed by Décamps et al. (2010) is interesting in that regard. These authors developed an assessment of the intensity of video game playing and the risk of its problematic use. This intensity may be thought as the magnitude of addictive behaviours and cognitions (e.g., preoccupation to play) reported by the players. The principle is that rather than being or not being addicted to video games considering a symptom checklist, players play with a certain intensity in the consumption behaviour, flow or cognitive investment. And it is hypothesized that intensity might be a risk factor to develop an IGD. The intensity of video gaming was scored on four levels from low intensity to intense or severe intensity which interprets as a high risk of developing an IGD.

IGD refers to pathological gaming with intense and recurrent gaming associated with clinical distress and impairment characterized by symptoms such as preoccupation, withdrawal, tolerance, unsuccessful attempts to stop or reduce, loss of interest in other hobbies or activities, excessive gaming despite problems, deception, escape or relief from a negative mood, jeopardized or lost relationship, job,

\footnotetext{
Corresponding author.

E-mail address: emin.altintas@univ-lille.fr (E. Altintas).
} 
educational or career opportunity. These negative consequences of IGD were found in different life domains such as health, school, work, or social interaction (Grüsser et al., 2007; Chappell et al., 2006; Wan and Chiou, 2006). Many psychological and mental distress are reported in the IGD context such as depression, negative self-esteem, social anxiety and Ioneliness (Caplan, 2007; Kim and Davis, 2009; Mihara and Higuchi, 2017; Zajac et al., 2017; Wang et al., 2018) and also sleep disturbances (Higuchi et al., 2005).

Researchers suggested that sleep disturbances are highly present and common in the general population, but also within video game players (Lam, 2014). In fact, electronic media exposure time is described as the origin of decreasing sleep duration (Twenge et al., 2017), and as affecting the sleep-wake cycle (Arrona-Palacios, 2017). In addition, sleep disturbance has been observed as a comorbidity and represents a central issue in gaming (Hastings et al., 2009; Hsu et al., 2012; Vandewater et al., 2014). Gaming duration could be related to some negative consequences on social relationships, school achievement and also sleep (Cain and Gradisar, 2010; Wolfe et al., 2014). In particular, King et al., (2014) reported an association between prolonged violent video gaming and poorer sleep efficiency in an adolescent population. In the same vein, Shochat et al. (2010) related video game playing time to poorer sleep. Exelmans and Van den Bulck (2015), using the PSQI also showed that video gaming was a significant predictor of bad sleep quality, fatigue and insomnia. Although not focused on sleep disorders, Turel et al. (2017) reported reduced sleep quality measured by the PSQI in a cohort of 125 children/adolescents video game players from 9 to 17 years old. The same conclusions were made by Parent et al. (2016) and Lange et al. (2017).

But, the majority of the studies explored effects of video game in terms of playing duration. In this study, we expected to find relationships between video game playing and several factors: video game duration, intensity of video game playing, sleep quality, and physical and mental health. The aim of this study was to determine and characterize sleep quality profiles in our sample with different subgroups (e.g., low, moderate, high sleep quality group), and identify which variables can significantly contribute to sleep quality: we hypothesized that intensity of play should be a better predictor than game duration for sleep quality which in turn should be associated with better health indicators.

\section{Methods}

\subsection{Participants and procedure}

Our sample comes from several gaming websites and consisted of 217 French online video game players who were active members of several online gaming forums. It was composed of 175 males and 42 females with a mean age of $24.40 \pm 6.98$ years. Moreover, the educational level was measured: 25 participants have a middle school level or a professional certificate, 64 participants have a high school education level and 75 participants have a Bachelor, 51 participants have a Masters degree, one participant had a Ph.D, and one had not indicated his educational level.

No financial compensation was provided. With the agreement of the webmasters, an invitation on the forum that invited all members to participate in the study was deposited. Free and informed consent was obtained, and participants were entitled to a presentation on the purpose of the study. After a description of the questionnaire, all volunteer members of these forums completed, in a first part, the consent form and were invited, in a second part, to respond anonymously and individually to an online questionnaire that assessed sociodemographic data, sleep quality, physical and mental health and intensity of video game playing. The average completion time was between 15 and $20 \mathrm{~min}$.

A reminder was made a month after the first broadcast of the questionnaire. The online questionnaire method has already been used in several studies in the field of video games and has been described as a satisfactory method (Achab et al., 2011).

\subsection{Measures}

The online questionnaire was designed to assess participants' sociodemographic data, sleep quality, and video game behaviors. It was composed of descriptive data (age, gender, educational level, professional status), sleep questionnaire (the Pittsburg Sleep Quality Index PSQI), physical and mental health questionnaire (The Medical Outcomes Study (MOS) 36-Item Short-Form Health Survey-MOS SF-36), video game duration per week, and intensity of video game playing questionnaire (AIE-Q).

\subsubsection{Sleep quality}

The Pittsburg Sleep Quality Index (PSQI) assessed self-reported sleep quality using 19-items (Buysse et al., 1989). Measurement concerns the past month sleep habits with seven dimensions of sleep: subjective sleep quality, sleep latency, sleep duration, sleep efficiency, sleep disturbance, sleep medication, and daytime sleepiness. For each item, respondents indicated their answer using a four-point Likert scale from 0 to 3 , and a summation of all item-scores (range 0 to 21) reported the global sleep quality (PSQI total score). Higher scores indicate worse sleep quality. The French version of the PSQI presents good psychometric properties with satisfactory validity and reliability within a French cohort (Blais et al., 1997). In this study, the internal consistency of the PSQI was satisfactory $(\alpha=0.67)$. Finally, the PSQI has a high sensitivity in clinical practice; a global score of PSQI over 5 points indicates a poor sleep quality (cut-off score over 5 indicates poor sleep quality) (Buysse et al., 1989; Carpenter and Andrykowski, 1998). As described in the original paper of Buysse et al. (1989), a global PSQI score $>5$ yielded a diagnostic sensitivity of $89.6 \%$ and specificity of $86.5 \%$ (kappa $=0.75 ; p<.001$ ) in distinguishing good and poor sleepers.

\subsubsection{Physical and mental health}

The 36-item Short-Form (SF-36) Health Survey, a generic measure of health including 36-items, assessed eight different dimensions of health: physical functioning (PF), bodily pain (BP), role limitations due to physical health problems (RP), role limitations due to personal or emotional problems (RE), general mental health $(\mathrm{MH})$, social functioning (SF), energy/fatigue or vitality (VIT), and general health perceptions $(\mathrm{GH})$ (Ware, and Sherbourne, 1992). Higher scores indicate a better health (range 0 to 100). These eight subscales can be aggregated in two general dimensions of health: physical health and mental health The French version of the SF-36 presents excellent psychometric properties, such as validity and reliability within French young adults (Perneger et al., 1995). In this study, the internal consistency of the SF36 was satisfactory $(\alpha=0.79)$.

\subsubsection{Intensity of video game playing}

The AIE-Q is a 14-item self-report measure of intensity of video game playing and the risk of its problematic use (Décamps et al., 2010). The questionnaire was built in line with the addiction criteria of DSM III-R adapted to a video game context. This scale explored different behavioral and cognitive dimensions in video game playing (e.g., impossibility to resist and perform the behavior, increasing sensation of tension before initializing the behavior, pleasure or relief during its realization, feeling of loss of control during the behavior). Respondents indicated how much each item corresponded to them using a sevenpoint Likert scale from 1 ("strongly disagree") to 7 ("strongly agree"). Responses were summed, and the total scores evaluated the intensity of video game playing from 14 to 98 with higher scores corresponding to a higher or severe intensity. The AIE-Q could identify 4 different video game playing intensities: low (from 14 to 27), moderate (from 28 to 43), high (from 44 to 52 ), and intense or severe intensity (from 53 to 
98). The authors reported satisfactory psychometric properties in a French cohort (Décamps et al., 2010). In this study, the internal consistency of the AIE-Q was satisfactory $(\alpha=0.84)$.

\subsection{Statistical analyses}

SPSS ${ }^{\circledR}$, version 20 (IBM Corporation, Armonk NY, USA) software was used to analyze data collection. First, descriptive and correlational statistics were conducted on the variables of the study. Second, we performed a hierarchical cluster analysis to determine the different sleep quality profiles or subgroups in our sample. Cluster Analysis enables us to identify subgroups that could not have been found with classical categorizations as cut-off score (Berjot et al., 2017; Henry et al., 2005; Yim and Ramdeen, 2015). Using cut-off score in PSQI could determine two sleep quality groups: good and poor. Naturally, more groups can potentially emerge from the analysis (e.g., poor, moderate and good sleep quality groups). Empirically and theoretically, the identification these groups is important. In the specific case of sleep quality, cluster analysis can exceed the 'all or nothing' conceptualizations and to identify specific subgroups on the basis of their responses on PSQI (e.g., moderate sleep quality group).

These analyses allowed us to identify and characterize different sleep quality profiles within our population (Hair et al., 2009). The different sleep profiles previously found were compared. Finally, a logistic regression was used to determine the effects of the variables of the study on the sleep quality.

\section{Results}

\subsection{Descriptive analysis}

The Table 1 indicates that online video gamers have a mean video game play time duration per week of $18.14 \pm 17.90 \mathrm{~h}$, and they report a mean PSQI score of $6.24 \pm 3.12$.

One hundred and twenty participants $(55.30 \%)$ reported a poor sleep quality, and ninety seven $(44.70 \%)$ participants were good sleepers.

Four groups with different intensity of video game playing were found: Fourty participants $(18.43 \%)$ as "low intensity video game players", ninety nine participants $(45.62 \%)$ as "moderate intensity video game players", fourty participants (18.43\%) as "high intensity video game players" and thirty eight participants (17.51\%) were classified as "intense video game players" on the basis of AIE-Q scores. Means and standard deviations of the studied variables as well as their subscales are reported in Table 1.

No difference was found between male and female for age $\left(t_{215}=-0.62, p=.53\right)$, sleep quality $\left(t_{215}=-1.61, p=.11\right)$, intensity of video game playing $\left(t_{215}=1.48, p=.14\right)$, physical health $\left(t_{215}=-0.36, p=.72\right)$, mental health $\left(t_{215}=0.14, p=.88\right)$; except for video game duration $\left(t_{215}=4.19, p=.001\right)$. Male $(M=20.55$ per week) reported more game duration than female $(M=8.11$ per week).

No significant correlation was found between PSQI global score and video game variables (video game duration: $r=-0.035, n s$; intensity of video game playing, $r=-0.093, n s$ ), and between PSQI global score and health variables (physical health, $r=0.049$, ns; mental health, $r=0.096, n s$ ) (Table 1). The lack of significant correlation between the variables of the study, and the level of repartition between poor sleepers and good sleepers, lead us to question the structuring of the PSQI data with cluster analysis. We hypothesized that we were going to most likely find different homogeneous sleep quality subgroups among the sample that could not have been found by using cut-off score of PSQI.

\subsection{Hierarchical cluster analysis}

The hierarchical cluster analysis with Ward's method, squared Euclidean distance was carried out on the seven dimensions of PSQI to determine the optimal number of sleep quality profiles in our sample (Hair et al., 2009; Yim and Ramdeen, 2015). We expected to obtain more than two sleepers subgroups but the cluster analysis has been in favor of a division into two profiles. Means and standard deviations of the seven PSQI subscales are reported in Table 2 and are presented in Fig. 1. The two sleep quality profiles found were: (1) "High sleep quality profile" for $132(60.83 \%)$ participants, and (2) "Low sleep quality profile" for 85 (39.17\%) participants (Table 2).

\subsection{Comparison between the two sleep quality profiles}

The Low sleep quality profile was characterized by significant lower levels of subjective sleep quality $\left(t_{215}=-13.12, p<.001\right)$, sleep efficiency $\left(t_{215}=-4.91, p<.001\right)$, higher levels of sleep latency $\left(t_{215}=-16.47, p<.001\right)$, sleep disturbance $\left(t_{215}=-6.23, p<.001\right)$, and sleep medication $\left(t_{215}=4.056, p<.001\right)$ compared to the high sleep quality profiles. No significant difference was found for sleep duration, daytime functioning and global PSQI score between the two profiles (Table 2). These significant differences reflected two distinct sleep quality profiles in our sample, and outlined several components of a worsened quality of sleep in the low-quality profile.

Moreover, players with a low sleep quality profile were those who

Table 1

Descriptive statistics (Mean and Standard Deviation) and correlations for sleep, health and video game variables.

\begin{tabular}{|c|c|c|c|c|c|c|c|c|c|c|c|c|c|c|}
\hline & Mean & $S D$ & 1. & $2 a$. & $2 \mathrm{~b}$ & $2 \mathrm{c}$. & $2 d$ & $2 \mathrm{e}$ & $2 f$. & $2 \mathrm{~g}$. & $2 \mathrm{~h}$. & 3. & 4. & 5. \\
\hline 1. Age & 24.4 & 6.98 & & & & & & & & & & & & \\
\hline \multicolumn{15}{|l|}{ Sleep subscales } \\
\hline 2a. Subjective sleep quality & 2.12 & 0.86 & -0.013 & & & & & & & & & & & \\
\hline 2b. Sleep latency & 1.16 & 0.94 & 0.007 & $0.472^{*}$ & & & & & & & & & & \\
\hline 2c. Sleep duration & 0.63 & 0.69 & -0.063 & -0.01 & -0.064 & & & & & & & & & \\
\hline 2d Sleep efficiency & 0.26 & 0.62 & 0.063 & $0.237^{*}$ & $0.374^{*}$ & -0.117 & & & & & & & & \\
\hline 2e. Sleep disturbance & 0.96 & 0.58 & 0.099 & $0.385^{\star}$ & $0.407^{*}$ & -0.08 & $0.259^{*}$ & & & & & & & \\
\hline 2f. Sleep medications & 0.16 & 0.61 & -0.03 & $0.199^{*}$ & $0.251^{*}$ & $-0.152^{*}$ & 0.132 & $0.197^{*}$ & & & & & & \\
\hline 2g. Daytime dysfunction & 0.95 & 0.81 & -0.013 & 0.049 & 0.047 & 0.107 & 0.055 & 0.055 & 0.017 & & & & & \\
\hline 2h. Global PSQI & 6.24 & 3.12 & -0.042 & 0.015 & -0.088 & $0.492^{*}$ & -0.082 & 0.013 & -0.076 & $0.578^{*}$ & & & & \\
\hline \multicolumn{15}{|l|}{ Health subscales } \\
\hline 3. Physical health & 55.58 & 10.50 & -0.101 & $-0.385^{*}$ & $-0.329^{*}$ & 0.071 & $-0.257^{*}$ & $-0.584^{*}$ & $-0.436^{*}$ & -0.005 & 0.049 & & & \\
\hline 4. Mental health & 41.85 & 16.15 & 0.088 & $-0.555^{\star}$ & $-0.376^{*}$ & 0.108 & $-0.217^{*}$ & $-0.459^{*}$ & $-0.342^{*}$ & 0.000 & 0.096 & $0.674^{*}$ & & \\
\hline \multicolumn{15}{|l|}{ Video game variables } \\
\hline 5. Video game duration & 18.14 & 17.90 & -0.052 & 0.082 & -0.005 & -0.086 & 0.03 & -0.034 & 0.283 & -0.013 & -0.035 & $-0.182^{*}$ & -0.099 & \\
\hline $\begin{array}{l}\text { 6. Intensity of video game } \\
\text { playing }\end{array}$ & 40.00 & 14.25 & -0.119 & $0.303^{*}$ & $0.236^{*}$ & -0.027 & 0.12 & $0.306^{*}$ & $0.298^{*}$ & -0.075 & -0.093 & $-0.415^{*}$ & $-0.389^{*}$ & $0.369^{*}$ \\
\hline
\end{tabular}

Note:

${ }^{*} p<.01 ;{ }^{* *} p<.001$ 
Table 2

Comparison between video game, sleep and health variables among two sleep quality profiles.

\begin{tabular}{|c|c|c|c|c|c|c|}
\hline & \multicolumn{2}{|c|}{$\begin{array}{l}\text { "High sleep quality } \\
\text { profile" }(n=132) \\
(60.83 \%)\end{array}$} & \multicolumn{2}{|c|}{$\begin{array}{l}\text { "Low sleep quality } \\
\text { profile" }(n=85) \\
(39.17 \%)\end{array}$} & \multirow[t]{2}{*}{$t$-value } & \multirow[t]{2}{*}{$p$} \\
\hline & Mean & SD & Mean & SD & & \\
\hline Age & 24.02 & 6.77 & 24.64 & 7.31 & 0.631 & 0.53 \\
\hline Gender & 1.22 & 0.38 & 1.17 & 0.42 & -0.895 & 0.37 \\
\hline Educational level & 4.59 & 1.31 & 4.60 & 1.20 & 0.084 & 0.93 \\
\hline $\begin{array}{l}\text { Professional } \\
\text { status }\end{array}$ & 2.95 & 1.25 & 3.11 & 1.34 & 0.894 & 0.37 \\
\hline \multicolumn{7}{|l|}{$\begin{array}{l}\text { Video game } \\
\text { variables }\end{array}$} \\
\hline $\begin{array}{l}\text { Video game } \\
\text { duration }\end{array}$ & 17.52 & 14.87 & 19.12 & 21.85 & -0.643 & 0.01 \\
\hline $\begin{array}{l}\text { Intensity of video } \\
\text { game playing }\end{array}$ & 37.21 & 11.51 & 44.33 & 16.86 & -3.699 & 0.01 \\
\hline \multicolumn{7}{|l|}{ Sleep subscales } \\
\hline $\begin{array}{l}\text { Subjective sleep } \\
\text { quality }\end{array}$ & 1.66 & 0.56 & 2.84 & 0.75 & -13.119 & 0.01 \\
\hline Sleep latency & 0.60 & 0.55 & 2.04 & 0.73 & -16.469 & 0.01 \\
\hline Sleep duration & 0.65 & 0.68 & 0.59 & 0.71 & 0.659 & 0.51 \\
\hline Sleep efficiency & 0.11 & 0.33 & 0.51 & 0.84 & -4.908 & 0.01 \\
\hline Sleep disturbance & 0.78 & 0.53 & 1.25 & 0.55 & -6.228 & 0.01 \\
\hline Sleep medications & 0.03 & 0.27 & 0.37 & 0.88 & -4.056 & 0.01 \\
\hline $\begin{array}{l}\text { Daytime } \\
\text { dysfunction }\end{array}$ & 0.89 & 0.77 & 1.04 & 0.85 & -1.262 & 0.21 \\
\hline $\begin{array}{c}\text { Global PSQI } \\
\text { Health subscales }\end{array}$ & 6.36 & 2.99 & 6.07 & 3.32 & 0.657 & 0.51 \\
\hline Physical health & 51.04 & 7.05 & 58.49 & 13.11 & 5.426 & 0.52 \\
\hline Mental health & 32.61 & 12.93 & 47.80 & 16.37 & 7.597 & 0.01 \\
\hline
\end{tabular}

Note: $N=217$. M: mean. SD: Standard Deviation

PSQI (Pittsburgh Sleep Quality Index)

had greater levels of video game duration $\left(t_{215}=-0.64, p<.001\right)$ but also greater intensity of video game playing $\left(t_{215}=-3.70, p<.001\right)$. They also had lower levels of mental health than those with a high sleep quality profile $\left(t_{215}=7.60, p<.001\right)$. Together, no significant difference was found between these two profiles for age, gender, educational level, professional status, and physical health (Table 2).

\subsection{Binomial logistic regression analysis}

Binomial logistic regression was performed on the sleep quality
Table 3

Binomial logistic regression results with sleep quality profile (High/Low) as dependent variable.

\begin{tabular}{llll}
\hline Variables & OR & $95 \%$ confidence interval & $P$ value \\
\hline Age & 1.021 & 0.962 .1 .083 & 0.49 \\
Gender & 0.818 & 0.368 .1 .819 & 0.62 \\
Educational level & 0.958 & 0.745 .1 .232 & 0.74 \\
Professional status & 1.059 & 0.772 .1 .453 & 0.72 \\
Online video game type & 0.975 & 0.855 .1 .112 & 0.72 \\
Video game duration & 1.020 & 0.998 .1 .042 & 0.08 \\
Intensity of video game playing & $0.969^{*}$ & 0.946 .0 .993 & 0.01 \\
Physical health & 1.005 & 0.964 .1 .048 & 0.81 \\
Mental health & $1.030^{*}$ & 1.005 .1 .056 & 0.02 \\
\hline
\end{tabular}

Note. $N=217$;

* $: p<.05 ;$ OR: Odd ratio

profiles (low and high sleep quality profile) as dependent variables. This analysis is used to measure the size effect of one factor for the risk of having low sleep quality. The significant level was fixed at $p<.05$, Odds Ratio $(\mathrm{OR})=1$ indicates no relationship between factor and the risk of having low sleep quality, Odds Ratio $(O R)<1$ indicates a decrease in the risk factor, while Odds Ratio $(O R)>1$ indicates an increase in the risk factor. When the Odds Ratio $(O R)=2$, then the risk is doubled. Age, gender, educational level, professional status, online video game duration per week, intensity of video game playing, physical health and mental health were retained as independent variables in a logistic regression analysis. The results found a significant contribution of two variables on sleep quality profile: (1) mental health $(\mathrm{OR}=1.030$; IC95 (1.005-1.056), $p<.05)$ and $(2)$ intensity of video game playing (OR $=0.969$; IC95 $(0.946-0.993), p<.05)$. The logistic regression analysis revealed that the video game players with high intensity of video game playing have an increased risk of low sleep quality; and the video game players with better mental health have a lower risk of low sleep quality. The other independent variables did not significantly contribute to the sleep quality profiles (Table 3 ). In particular, no significant effect was found for video game duration. Finally, mental health has positive effects on sleep quality while intensity of video game playing represents a risk factor for sleep quality with negative effects.

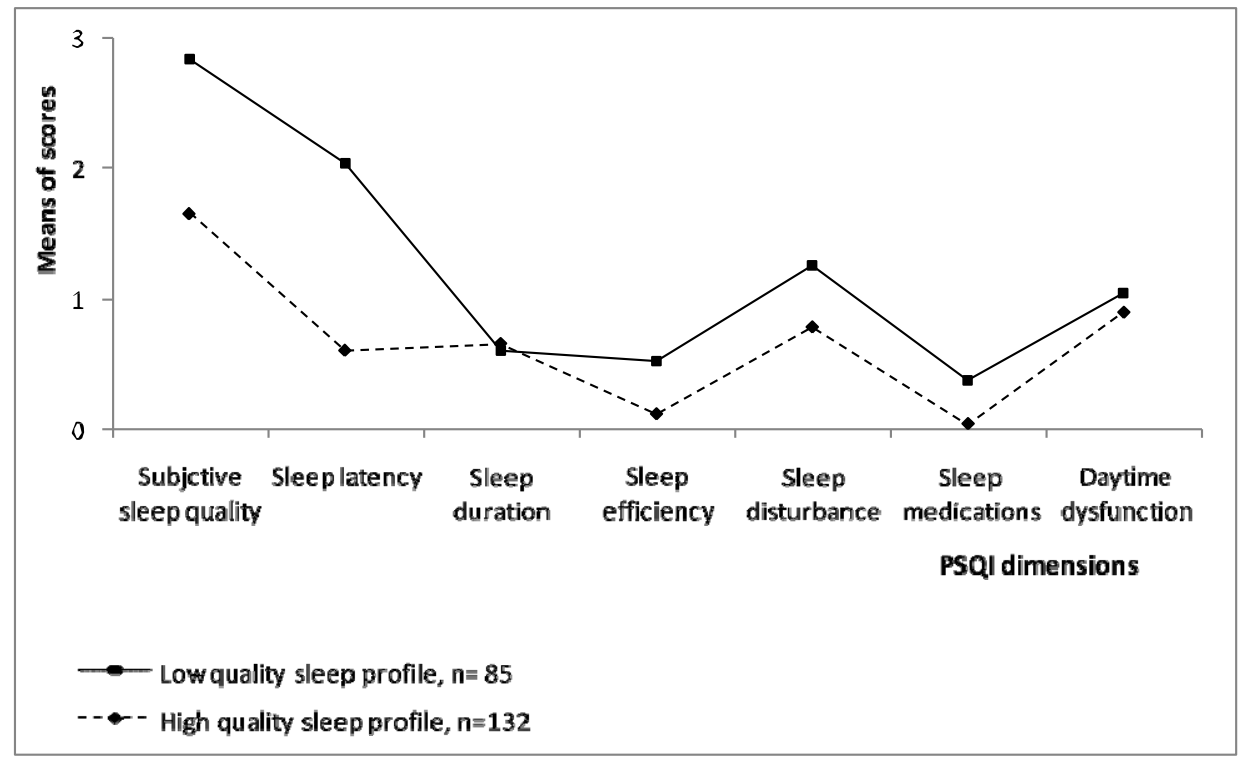

Fig. 1. Two sleep quality profiles in online video game player. 


\section{Discussion}

One hundred and twenty (55.30\%) participants reported a poor sleep quality, and $38(17.51 \%)$ participants reported a severe intensity of video game playing in our sample with using the cut-off scores. These results support the assumption that sleep disturbance and problematic video game use represent a central issue in young populations. However the poor sleep quality was not limited to the problematic video gamers only. But a relationship between video game playing and poor sleep quality could exist.

Cluster analysis allowed to identify and characterize different sleep quality subgroups in the sample. Consequently, homogeneous subgroups on sleep quality were determined. Two sleep quality profiles emerged from our sample: (1) video gamers with a high sleep-quality profile and (2) video gamers with a low sleep-quality profile. The profiles differed in every subscales of PSQI, except daytime functioning and sleep duration. Video game players with a low sleep quality profile were more likely to have a worse subjective sleep quality, a long sleep latency, a worse sleep efficiency, a bigger sleep disturbance and a more frequent use of sleep medication than video gamers with a high sleep quality profile. No difference was found for daytime functioning and sleep duration. This is in line with previous studies showing that sleep structure is affected by screen exposure (Dworak et al., 2007; King et al., 2013; Higuchi et al., 2005; Van den Bulck, 2004). As a matter of fact, it has been demonstrated that video screens display blue light which in turn, blocks the melatonin release, one of the most important hormone involved in sleep onset (Van der Lely et al., 2015; Van den Maren et al., 2018).

In addition, these results have reported in the group of gamers with a low sleep quality, a higher video game duration, a higher intensity of video game playing and a lower mental health level compared to the group with high sleep quality. No difference was found for physical health. The results allowed to relate poor sleep quality, intensity of video game playing and mental health in French online video game players. In other words, high intensity video game playing could conduce to decreased sleep quality and affect mental health. In sum, video game playing could have negative consequences in term of sleep quality and health. However Rusnac et al. (2018) reported sleep deprivation could also produce or enhance risk-taking and sensation seeking (e.g., in video game playing). In turn, poor sleep quality could maintain and increase video game playing and affect mental health. These relationships between video game playing, sleep and health should be deeper explored to determine the way they interact.

On the basis of these results, one question emerged: duration or intensity? In fact, the relationship between video gaming duration and sleep has been clearly established in previous studies (Turel et al., 2017; Exelmans and Van den Bulck, 2015; King et al., 2013; Schochat, et al., 2010). However video game duration assessment in IGD is necessary but not sufficient (Smith et al., 2017). We have used video game duration and intensity of video game playing (AIE-Q), including behavioral and cognitive dimensions, to assess and characterize video game behaviors. Intensity refers to the degree or magnitude of preoccupation and using video game behaviour, which range on a intensity continuum from low to severe (with high risk of maladaptive patterns of video game behaviour), and it seems complementary to duration assessment in the evaluation of individual video game behaviour. The assessment of intensity of video game playing with (AIE-Q) is based on addiction criteria of DSM III-R. This intensity assessment used in the study has satisfactory psychometric values, but is limited and need to update in line with the recent evolution in video game research such as the Internet Gaming Disorder (IGD) classification descripted in the DSM-V section III (APA, 2013).

Finally, the results of the present study highlighted two factors which were significant predictors for sleep quality in video game playing. First, mental health had a positive effect on sleep quality. Second, intensity of video game playing had a negative effect on sleep quality and represented a risk factor for worsened sleep quality. Video game duration and physical health were not significant predictors of sleep quality. All together intensity of video game playing and mental health were more salient factors to predict a poor sleep quality than video game duration and physical health. These results extend the previous studies on the negative impact of problematic video game playing, as it is known that there is an association between high duration of video game playing and low sleep quality (King et al., 2013; Shochat et al., 2010). By contrast, video game duration, gender, age educational level and professional status were not significant predictors of sleep quality in our sample composed of video game players. These findings provide a clear contribution to the relationship between sleep quality and video game playing in gamers. The video game duration appears to be a non-relevant variable in the general population. The analysis of sleep quality in the light of intensity of video game playing is an original approach and contributes somehow to a better understanding of the sleep disturbance process in video game playing in the general population: (1) Poor sleep quality was found in problematic video game players but also in non-problematic video game players, (2) intensity of video game playing was a more relevant factor to characterize the video game players than video game duration, (3) intensity of video game playing was a salient risk factor and mental health was a protective factor to sleep quality in general population.

Several limitations are present in this study. First, the number of participants in our sample was limited to only two hundred and seventeen, and the recruitment took place exclusively via French gaming websites. Second, the study concerned the general population playing video game on online websites and not a clinical population suffering addictive behaviors, and this might generate a self-selection bias (e.g., social desirability). Third, the use of an online questionnaire can constitute another limitation of the study with self-selection bias. Fourth, the $A E I-Q$ is limited and need to adapt in line the recent developments in the IGD researches.

Our priority in future research will be to explore the intensity of video game playing in a more specific way with a larger sample of characteristics and develop specifically adapted questionnaire. We will also focus on a clinical populations in order to go further in the knowledge of these complex interactions. This study focused on overall health quality and we will also explore in a more detailed manner the mental health area and its link with sleep disturbance caused by video game playing. We think that intensity of video game playing is an interesting concept and that it should be investigated in the context of IGD.

\section{Conclusion}

This pilot study successfully reported two essentials factors to the sleep process in online video gamers: mental health represents a protective factor for sleep quality, while intensity of video game playing represents a risk factor. These findings could clearly contribute to improve clinical practice within this specific population. In clinical practice, the video game duration is necessary but not sufficient to understand more extensively the human-video game interaction and its negative consequences (e.g., sleep disturbance).

\section{Conflict of interest}

The authors declared no potential conflicts of interests with respect to the authorship and/or publication of this article.

\section{Acknowledgement}

The author would like to thank all participants. 


\section{References}

Achab, S., Nicolier, M., Mauny, F., Monnin, J., Trojak, B., Vandel, P., et al., 2011 Massively multiplayer online role-playing games: Comparing characteristics of addict vs non-addict online recruited gamers in a French adult population. BMC Psychiatry 11 (144), 156.

American Psychiatric Association, 2013. Diagnostic and Statistical Manual of Mental Disorders, 5th ed. Author, Arlington, VA.

Arrona-Palacios, A., 2017. High and low use of electronic media during nighttime before going to sleep: a comparative study between adolescents attending a morning or afternoon school shift. J. Adolesc. 61, 152-163.

Berjot, S., Altintas, E., Grebot, E., Lesage, F.-X., 2017. Burnout risk profiles among French psychologists. Burnout Res. 7, 10-20.

Billieux, J., Schimmenti, A., Khazaal, Y., Maurage, P., Heeren, A., 2015. Are we overpathologizing everyday life? A tenable blueprint for behavioral addiction research. J. Behav. Addict. 4 (3), 119-123.

Blais, F.C., Gendron, L., Mimeault, V., Morin, C.M., 1997. Evaluation de l'insomnie : validation de trois questionnaires. L'Encéphale 23, 447-453.

Buysse, D.J., Reynolds, C.F., Monk, T.H., Berman, S.R., Kupfer, D.J., 1989. The Pittsburgh Sleep Quality Index: a new instrument for psychiatric practice and research. Psychiatry Res. 28, 193-213.

Cain, N, Gradisar, M., 2010. Electronic media use and sleep in school-aged children and adolescents: a review. Sleep Med. 11 (8) 735e42, 2010.

Caplan, S.E., 2007. Relations among loneliness, social anxiety, and problematic internet use. Cyberpsychol. Behav. 10, 234-242.

Carpenter, JS, Andrykowski, MA., 1998. Psychometric evaluation of the Pittsburgh Sleep Quality Index. J. Psychosom. Res. 45, 5-13.

Chappell, D., Eatough, V., Davies, M.N.O., Griffiths, M.D., 2006. EverQuest-it's just a computer game right? An interpretative phenomenological analysis of online gaming addiction. Int. J. Ment. Health Addict. 4, 205-216.

Décamps, G., Battaglia, N., Idier, L., 2010. Elaboration of the Addictive Intensity Evaluation Questionnaire (AIEQ): evaluation of addictive behaviors and co-addictions with or without substances. Psychologie Française 55, 279-294.

Dworak, M., Schierl, T., Bruns, T., Strüder, H.K., 2007. Impact of singular excessive computer game and television exposure on sleep patterns and memory performance of school-aged children. Pediatrics 120 (5), 978-985.

Exelmans, L., Van den Bulck, J., 2015. Sleep quality is negatively related to video gaming volume in adults. J. Sleep Res. 24 (2), 189-196.

Gentile, D., 2009. Pathological video-game use among youth ages 8 to 18: a national study. Psychol. Sci. 20, 594-602.

Gentile, D.A., Bailey, K., Bavelier, D., Brockmyer, J.F., Cash, H., Coyne, S.M., et al., 2017.

Internet gaming disorder in children and adolescents. Pediatrics 140, 81-S85. Grüsser, S.M., Thalemann, R., Griffiths, M.D., 2007. Excessive computer game playing: evidence for addiction and aggression? Cyberpsychol. Behav. 10, 290-292.

Hair, J.F., Black, W.C., Babin, B.J., Anderson, R.E., 2009. Multivariate Data analysis? 7th Ed. Prentice Hall, Upper Saddle River, NJ.

Hastings, EC, Karas, TL, Winsler, A, et al., 2009. Young children's video/computer game use: relations with school performance and behavior. Issues Ment. Health Nurs. 30 (10), $638 \mathrm{e} 49$

Henry, D.B., Tolan, P.H., Gorman-Smith, D., 2005. Cluster analysis in family psychology research. J. Family Psychol. 19 (1), 121-132.

Higuchi, S., Motohashi, Y., Liu, Y., Maeda, A., 2005. Effects of playing a computer game using a bright display on presleep physiological variables, sleep latency, slow wave sleep and REM sleep. J. Sleep Res. 14 (3), 267-273.

Hsu, W.Y., Chui, N-Y., Liu, J-T., Wang, C-H., Chang, T-G., Liao, Y-C., Kuo, P-I., 2012. Sleep quality in heroin addicts under methadone maintenance treatment. Acta Neuropsychiatrica 24, 356-360.

Inserm, 2014. Conduites addictives chez les adolescents: usages, prévention et accompagnement. Collection Expertise collective. Inserm, Paris.

Kim, H., Davis, K.E, 2009. Toward a comprehensive theory of problematic internet use: evaluating the role of self-esteem, anxiety, flow, and the self-rated importance of internet activities. Comput. Hum. Behav. 25, 490-500.

King, DL, Gradisar, M, Drummond, A, Lovato, N, Wessel, J, et al., 2013. The impact of prolonged violent video-gaming on adolescent sleep: an experimental study. J. Sleep
Res. 2, 137-143.

King, D.L., Delfabbro, P.H., Griffiths, M.D., 2011. The role of structural characteristics in problematic video game play: an empirical study. Int. J. Mental Health Addict. 9 (3), 320-333.

Kuss, D.J., Griffiths, M.D., 2012. Internet gaming addiction: a systematic review of empirical research. Int. J. Mental Health Addict. 10 (2), 278-296.

Lam, L.T., 2014. Internet gaming addiction, problematic use of the internet, and sleep problems: a systematic review. Curr. Psychiatry Rep. 16 (4), 444.

Lange, K., Cohrs, S., Skarupke, C., Görke, M., Szagun, B., Schlack, R., 2017. Electronic media use and insomnia complaints in German adolescents: gender differences in use patterns and sleep problems. J. Neural Transm. 124 (Suppl 1), 79-87.

Mihara, S., Higuchi, S., 2017. Cross-sectional and Iongitudinal epidemiological studies of internet gaming disorder: a systematic review of the literature. Psychiatry Clin Neurosci. 71, 425-444.

Parent, J., Sanders, W., Forehand, R., 2016. Youth screen time and behavioral health problems: the role of sleep duration and disturbances. J. Dev. Behav. Pediatr. 37 (4), 277-284.

Perneger, T.V., Leplege, A., Etter, J-F., Rougemont, A., 1995. Validation of a French language version of the MOS 36-item short form health survey (SF-36) in young healthy adults. J. Clin. Epidemiol. 48, 1051-1060.

Rusnac, N., Spitzenstetter, F., Tassi, P., 2018. Chronic sleep loss and risk-taking behavior: does the origin of sleep loss matter? Behav. Sleep Med. 20, 1-11.

Shochat, Flint-Bretner, Tzischinksy, O., 2010. Sleep patterns, electronic media exposure and daytime sleep-related behaviours among Israeli adolescents. Acta Paediatr 99, 1396-1400.

Smith, L.J., Gradisar, M., King, D.L., Short, M., 2017. Intrinsic and extrinsic predictors of video-gaming behaviour and adolescent bedtimes: the relationship between flow states, self-perceived risk-taking, device accessibility, parental regulation of media and bedtime. Sleep Med. 30, 64-70.

Turel, O., Romashkin, A., Morrison, K.M., 2017. A model linking video gaming, sleep quality, sweet drinks consumption and obesity among children and youth. Clin. Obes 7 (4), 191-198

Twenge, J.M., Krizan, Z., Hisler, G., 2017. Decreases in self-reported sleep duration among U.S. adolescents 2009-2015 and association with new media screen time. Sleep Med. 39, 47-53.

Van den Bulck, J., 2004. Television viewing, computer game playing, and internet use and self-reported time to bed and time out of bed in secondary-school children. Sleep 27 (1), 101-104.

Van der Lely, S., Frey, S., Garbazza, C., Wirz-Justice, A., Jenni, O.G., Steiner, R., et al., 2015. Blue blocker glasses as a countermeasure for alerting effects of evening lightemitting diode screen exposure in male teenagers. J. Adolesc. Health 56 (1), 113-119.

Van der Maren, S., Moderie, C., Duclos, C., Paquet, J., Daneault, V., Marie, D., 2018. Daily profiles of light exposure and evening use of light-emitting devices in young adults complaining of a delayed sleep schedule. J. Biol. Rhythms 33 (2), 192-202.

Vandewater, EA, Shim, MS, Caplovitz, AG, 2014. Linking obesity and activity level with children's television and video game use. J. Adolesc. 27 (1), 71e85.

Wan, C., Chiou, W., 2006. Why are adolescents addicted to online gaming? An interview study in Taiwan. Cyberpsychol. Behav, 9, 762-766.

Wang, H.R., Cho, H., Kim, D.-J., 2018. Prevalence and correlates of comorbid depression in a nonclinical online sample with DSM-5 internet gaming disorder. J. Affect. Disord. 226, 1-5.

Ware, J.E., Sherbourne, C.D., 1992. The MOS 36-item short-Form health survey (SF-36). I. Conceptual framework and item selection. Med. Care 30, 473-483.

Wolfe, J, Kar, K, Perry, A, et al., 2014. Single night video-game use leads to sleep loss and attention deficits in older adolescents. J. Adolesc. 37 (7), 1003 e9.

Yim, O., Ramdeen, K.T., 2015. Hierarchical cluster analysis: comparison of three linkage measures and application to psychological data. Quant. Methods Psychol. 11 (1), $8-21$.

Young, K.S., 1998. Internet addiction the emergence of a new clinical disorder CyberPsychol. Behav. 1, 237-244.

Zajac, K., Ginley, M.K., Chang, R., Petry, N.M., 2017. Treatments for Internet gaming disorder and Internet addiction: A systematic review. Psychology of Addictive Behaviors 31 (8), 979-994. 